\title{
Conceptions of Europe in Renaissance France. Essays in Honour of Keith Cameron, edited by David Cowling
}

\section{Michele Mastroianni}

\section{(2) OpenEdition}

\section{Journals}

\section{Edizione digitale}

URL: http://journals.openedition.org/studifrancesi/9812

DOI: $10.4000 /$ studifrancesi.9812

ISSN: 2421-5856

\section{Editore}

Rosenberg \& Sellier

\section{Edizione cartacea}

Data di pubblicazione: 1 octobre 2007

Paginazione: 424

ISSN: 0039-2944

\section{Notizia bibliografica digitale}

Michele Mastroianni, «Conceptions of Europe in Renaissance France. Essays in Honour of Keith Cameron edited by David Cowling», Studi Francesi [Online], 152 (LI | II) | 2007, online dal 30 novembre 2015, consultato il 09 janvier 2021. URL: http://journals.openedition.org/studifrancesi/9812 ; DOI: https:// doi.org/10.4000/studifrancesi.9812

Questo documento è stato generato automaticamente il 9 janvier 2021.

\section{(c) $(1)$}

Studi Francesi è distribuita con Licenza Creative Commons Attribuzione - Non commerciale - Non opere derivate 4.0 Internazionale. 


\title{
Conceptions of Europe in Renaissance France. Essays in Honour of Keith Cameron, edited by David Cowling
}

\author{
Michele Mastroianni
}

\section{NOTIZIA}

AA. VV., Conceptions of Europe in Renaissance France. Essays in Honour of Keith Cameron, edited by David cowling, Amsterdam-New York, Rodopi («Faux Titre», 281), 2006, pp. 204.

1 I saggi che D. Cowling ha riunito in onore di Keith Cameron hanno un'indubbia coerenza, incentrati come sono sulla nozione di Europa e sul rapporto Europa/ Cristianità quale si elabora nel Cinquecento. I contributi contenuti nella silloge sono i seguenti: Jean BALSAMO, 'Voici venir d'Europe tout l'Honneur': identité aristocratique et conscience européenne (pp. 21-34); Ian MORRISON, Rabelais: Christendom and Europe (pp. 35-53); Margaret M. MCGOWAN, Interpreting the past: the Commentaries of Blaise de Vigenère and 'l'enrichissement de nostre parler' (pp. 55-76); David TROTTER, 'Si le français n'y peut aller': Villers-Cotterêts and mixed-language documents from the Pyrenees (pp. 77-97); Yvonne BELLENGER, Sur 'La Lepanthe' de Du Bartas (pp. 99-116); Marie-Madeleine FRAGONARD, Aubigné et l'Angleterre, après Elizabeth: esquisse de rencontres problématiques (pp. 117-134); Yvonne ROBERTS, Towards a pragmatic recognition of religious diversity: the struggle to form a royalist consensus in the early poems of Jean-Antoine de Baif (pp. 135-152); Michael HEATH, Foolish or fearsome Franks? The supposed Ottoman view of European Christian in the sixteenth century (pp. 153-176); Françoise CHARPENTIER, Le périple des Pantagruéliens, ou l'ancien et le nouveau (pp. 177-191); Frank LESTRINGANT, Le Livre des Contrariétés: l'Occident, le Turc et les autres (pp. 193-204).

2 Una prima sezione della raccolta è consacrata al problema della definizione del concetto di Europa sul piano ideologico, cronologico e linguistico. Jean Balsamo 
sottolinea come, per quanto sia antistorico pensare a un'affermazione, nel Cinquecento, del concetto di Europa come entità politica, si affermi nel Rinascimento la consapevolezza di un'entità culturale che va ben al di là di una nozione puramente spaziale, geografica. Ian Morrison analizza, a partire dall'opera di Rabelais, le oscillazioni tra la nozione tradizionale di Cristianità, indebolita nel Quattro e Cinquecento a causa delle divisioni religiose, e quella di Europa, fornita di una identità culturale che si contraddistingue sempre più da quella degli altri continenti. Margaret McGowan affronta il problema della definizione dell'Europa moderna ai suoi albori a partire dall'analisi delle traduzioni e annotazioni di Blaise de Vigenère a testi greci e latini che denotano un'attenzione particolare a sviluppare le possibilità di espressione in lingua francese di concetti antichi. Anche David Trotter si muove sul piano linguistico esaminando dei documenti notarili e amministrativi, quali le Ordonnances di Villers-Cotterêts (1539): il plurilinguismo che caratterizza tali testi, ove si trova una mescolanza di elementi latini, francesi e guasconi, suggerisce che un'identificazione troppo frettolosa tra nazione e lingua nazionale sarebbe, all'epoca, sbagliata. Una seconda sezione offre esempi di coesione transnazionale all'inizio dell'epoca moderna, in particolare di scambi culturali e collaborazione politica tra Francia e Inghilterra durante le guerre di religione. Così, Yvonne Bellenger si sofferma su La Lepanthe di Du Bartas, poema epico, traduzione del poema The Lepanto di Giacomo VI di Scozia, esempio di come due autori protestanti celebrino un'impresa cattolica quale difesa della cristianità contro i Turchi e quale lotta dell'Europa contro l'Asia. Marie-Madeleine Fragonard studia i contatti politici che Agrippa d'Aubigné ebbe con il mondo inglese, dopo la morte della regina Elisabetta. Yvonne Roberts ripercorre nella prima produzione di Jean-Antoine de Baïf i testi di rilevanza politica, mettendo in evidenza l'idea di unità religiosa che il poeta, intorno al 1559, difende, nel quadro di una politica di unità nazionale intorno alla Corona. La terza sezione concerne il ruolo dell'al- terità e del relativismo culturale nella costruzione di un'identità europea nel cinquecento. Michael Heath disegna il ruolo del Turco nella letteratura satirica del xvi secolo, ruolo simile a quello che sarà del Persiano in Montesquieu, e il ruolo del Turco in una letteratura politica volta alla celebrazione della Francia, mediante l'affermazione di un preteso riconoscimento della grandezza militare francese da parte degli Ottomani, e volta alla giustificazione dell'alleanza dei Valois con i turchi. Françoise Charpentier mette in evidenza come nel Quart e nel Cinquiesme Livre di Rabelais frequenti allusioni alla Touraine e all'Europa servano da termine di paragone con le isole esotiche visitate da Pantagruel e dai suoi compagni, rafforzandone la percezione di alterità. Franck Lestringant, infine, rivolge l'attenzione a un genere letterario che ha fortuna tra il Cinque e il Seicento, quello del Livre des contrariétés, soffermandosi in particolare su quelle che sono eminentemente le figure del 'contrario' (il Siriano e il Turco) rispetto all'Europeo. 